Research Article

\title{
In vitro Technical Aspects of Anti-Gene IGF-I Vaccines against Glioma
}

Jerzy Trojan ${ }^{1,2^{*}}$, Gabriela Quintero ${ }^{1,3}$, Adama Ly ${ }^{1,2}$, Andrea Guzman ${ }^{1}$, Tatiana Castillo ${ }^{4}$, Carolina Rojas ${ }^{1}$, Jefferson Moreno ${ }^{1}$, Pedro Penagos ${ }^{5}$, Alexander Shevelev ${ }^{1,6}$, Herve O. Siachoque, Oscar Gutierrez ${ }^{8}$, Maciej Bierwagen ${ }^{9}$, Carlos Rojas ${ }^{3}$, Heliodor Kasprzak ${ }^{1,9}$, Tadeusz Popiela ${ }^{10}$, Adis Ayala ${ }^{4}$, Yuexin X. Pan ${ }^{11}$, Edwin Paez ${ }^{12}$, Diana M. Gomez ${ }^{12}$, Ricardo Santander ${ }^{1}$, Alvaro Alvarez ${ }^{13}$, Jaime Arias ${ }^{12}$, Luis E. Florez ${ }^{14}$, Donald D. Anthony ${ }^{11}$, Ignacio Briceno ${ }^{1,15}$, You-Chun Lone ${ }^{1,2}$, Annabelle Trojan ${ }^{1,13^{*}}$

${ }^{1}$ ICGT Bogota/Paris, Colombia and France

${ }^{2}$ Cancer Center, INSERM U602 \& UMR1197, Villejuif, France

${ }^{3}$ Faculty of Health Sciences, UNAB University, and Foscal Clinic, Floridablanca, Colombia

${ }^{4}$ Faculty of Science, Distrital University, Bogota, Colombia

${ }^{5}$ Department of Neurosurgery, INC- National Institute of Cancerology, Bogota, Colombia

${ }^{6}$ Cell Engineering Laboratory, Cardiology Institute, Moscow, Russia

'INS - National Institute of Health, and CEDEA, Bogota, Colombia

${ }^{8}$ Department of Neurosurgery, Hospital Kennedy, Bogota, Colombia

${ }^{9}$ Department of Neurosurgery, UMK University Hospital, Bydgoszcz, Poland

${ }^{10}$ Collegium Medicum, Jagiellonian University, Cracow, Poland

${ }^{11}$ School of Medicine, CWRU University, $\mathrm{OH}$, USA

${ }^{12}$ Faculty of Medicine, and Faculty of Science, UN - National University, Bogota, Colombia

${ }^{13}$ Faculty of Medicine, University of Cartagena, Cartagena de Indias, Colombia

${ }^{14} \mathrm{ClO}$ - Center of Oncologic Investigations, Bogota, Colombia

${ }^{15}$ Institute of Human Genetics, PUJ University, Bogota, Colombia

\begin{abstract}
Research on glioblastoma has demonstrated a significant increase in IGF-I gene expression in this brain tumor. After suppression of IGF-I expression using anti-gene IGF-I technologies, glioma cells become immunogenic, expressing MHC-I. While injected in vivo, they induce an immune response mediated by T-CD8 lymphocytes. These cells, applied as autologous anti-cancer vaccines have increased the median survival of glioblastoma patients up to 18 months, but often up to two-three years. These differences in clinical results could be explained by variability in vaccine preparation standards. For this reason, the conditions of in vitro preparation of anti-cancer vaccines were explored using antisense, AS, and triple helix, TH technology. The established human glioblastoma primary cell line, and an established rat cell line, C6 glioma, were transfected in vitro with IGF-I AS, and with IGF-I TH vectors producing arrest of the synthesis of IGF-I on transduction and transcription levels, respectively. An arrest in IGF-I gene expression was demonstrated in 50-60\% of cultured cells. The AS and TH cells expressed MHC-I only in $30-40 \%$ of cells. To increase the immunogenic population, the transfected cells were cloned to obtain $100 \%$ IGF-I negative population. These cloned cells expressed MHC-I and B7 antigens in $60-70 \%$ of cells. The presented in vitro results will be applied for preparation of cell vaccines for cancer immunotherapy, with the objective of increasing median survival in glioblastoma treated patients.
\end{abstract}

Keywords

Glioma cells, IGF-I, Anti-gene technology, Vaccines for cancer immunotherapy

\section{Introduction}

Gene expression during the neoplastic development of the brain, and especially during the appearance of malignant glioma, concerns various oncoproteins, as AFP, and growth factors and their receptors (IGF-I, EGF, FGF, VEGF, TGF alpha and beta and their signaling pathways PI3K/AKT including glycogen synthase) [1-4]. 


\section{CTGGAAGCTIFCTITICCCTCTCTCTCTCTTCCGGATCCCCTC \\ 3. GACCTTCGA AGANGAGGGAMGAGAGAGAGGCCTAGGGGA}

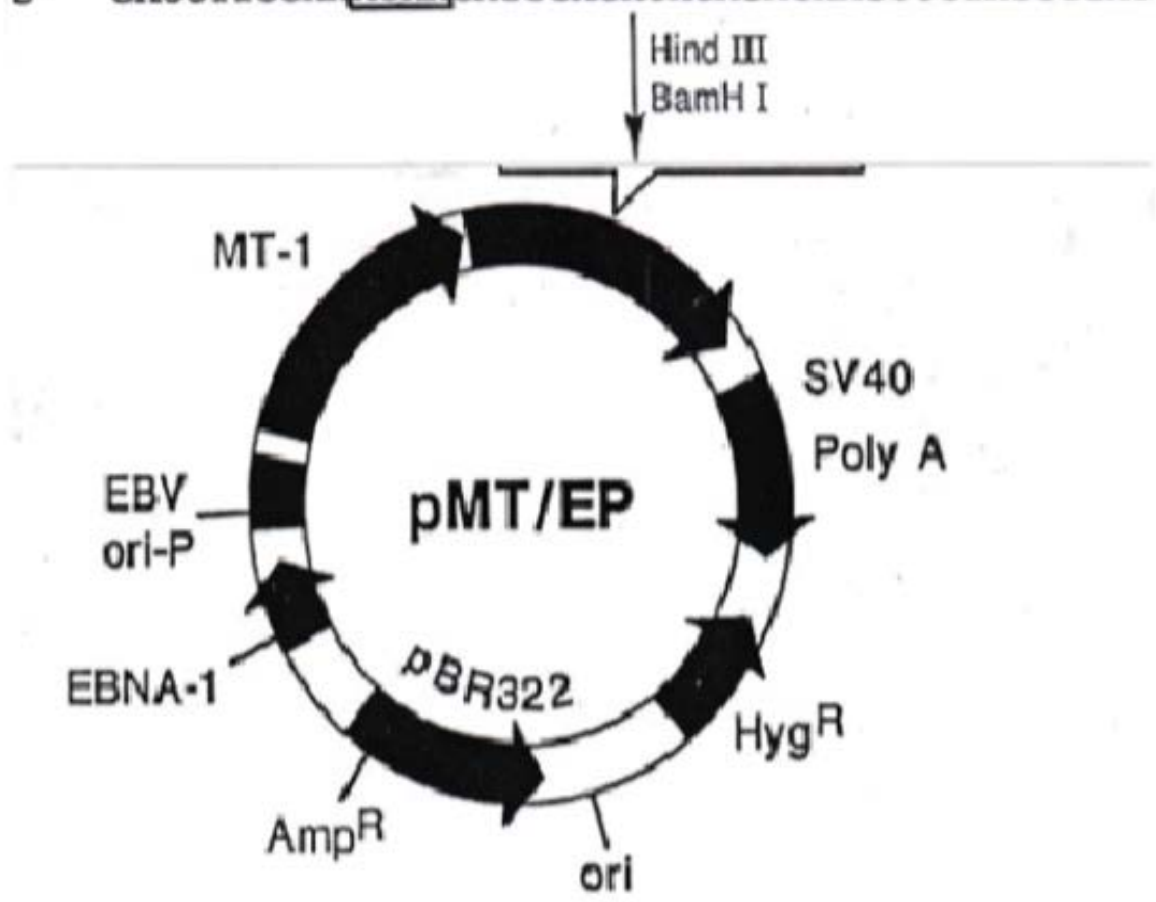

Figure 1: (left) Diagrammatic representation of IGF-I triple helix expression vector, the episomal vector construct, derivatived from pMT/EP (empty vector). In IGF-I antisense expression vector, cDNA of IGF-I (sequence of $536 \mathrm{bp}$ of exon 1) is inserted in antisense orientation [5].

5' CTGGAAGCTTTCTTCTCCCTCTCTCTCTCTTCCGGATCCCCTC

3' GACCTTCGAAAGAAGAGGGAGAGAGAGAGAAGGCCTAGGGGAG

To distinguish between neoplastic glial cells and neuroblasts, we used the IGF-I marker. In this case, glial cells gave positive reaction and neuroblastic cells, negative [5]. This observation suggested that targeting IGF-I gene expression we could stop the glial neoplastic development using anti-gene strategy [6].

The past forty years have accelerated the researches related to the treatment of tumors targeting the proteins using either antibodies i.e. anti AFP, or injection of radiolabelled oncoproteins was proposed [7]. Currently, the anti-gene strategies stopping the protein synthesis either on translation level (antisense, AS) [8] or transcription level (triple-helix, TH) [9] offer new possibilities for cancer therapy.

The antisense sequences are capable of blocking the messenger RNA translation conducting to block of specific protein synthesis. In another anti-gene approach, TH technology, specific oligonucleotide sequences also called triple helix-forming oligonucleotides, TFOs, while introduced into cells are linked to the genomic DNA forming the triple helix structure with the target gene and inhibiting its transcription [2,4,8-10]. A novel development in oligodeoxynucleotide technology is the relatively recent finding that 21-23 mer double-stranded RNA molecules, known as siRNA, can effectively silence gene expression [11]. Whether or not siRNA technology will sup- plant the classical oligodeoxynucleotide approaches is still in question at the moment, because we do not yet have the final clinical results [10].

Using AS and TH technologies we have obtained in both approaches, similar experimental and clinical results. The transfected AS and TH cells-autologous anti-cancer 'vaccines'expressed MHC-I and B7.1 and B7.2 antigens, and moreover became apoptotic. These cells induced in vivo T-cell mediated immune reaction against their tumorigenic progenitor's cells in syngeneic animals, with tumor regression at distal sites $[12,13]$. The objective of here presented article was to increase the usefulness of this strategy [6], by making more performant anti IGF-I vaccines. The ultime goal would be to increase of median survival of treated glioblastoma patients.

*Corresponding author: Dr. Jerzy Trojan, and Dr. Ignacio Briceno, ICGT and PUJ University, Bogota, Colombia, Tel: 57-320993-18-85, E-mail: genetherapy @hotmail.fr

Accepted: January 14, 2019

Published online: January 16, 2019

Citation: Trojan J, Quintero G, Ly A, et al. (2019) In vitro Technical Aspects of Anti-Gene IGF-I Vaccines against Glioma. Insights Biomed Res 3(1):43-48 
Citation: Trojan J, Quintero G, Ly A, et al. (2019) In vitro Technical Aspects of Anti-Gene IGF-I Vaccines against Glioma. Insights Biomed Res 3(1):43-48

\section{Materials and Methods}

\section{Vectors}

The IGF-I antisense and triple helix technologies were used to construct episome based plasmids either pMT-Anti-IGF-I expressing IGF-I RNA antisense, or pMT-AG inducing the IGF-I RNA-DNA triple helix (Figure 1). For control experiments, the vectors suppressing $\mathrm{MHC}-\mathrm{I}$ and $\mathrm{B} 7$ molecules, expressing antisense MHC-I and antisense B7 (MHC-I AS and B7 AS), as well as antisense IGF-II RNA expressing vector, were constructed as previously described. To stimulate the MT promotor, the cells were cultivated in presence of $60 \mathrm{uM} \mathrm{ZnSO}{ }_{4}[13,14]$.

\section{In vitro cells}

The rat cell line C6 was used for the experiments [8]. Primary cell cultures of human glioma were derived from tumors of glioblastoma multiforme patients during surgical resection in the INC-National Institute of Cancerology, Bogota. The human cell line, HG, was established according to the technique described previously [13]. As a control Hela cell line was used. In general, rat and human glioma cells were cultured in DMEM (GIBCO-BRL) supplemented with $10 \%$ FCS, $2 \mathrm{mM}$ glutamine, $100 \mathrm{U} / \mathrm{ml}$ penicillin and $100 \mathrm{ug} / \mathrm{ml}$ streptomycin, at $37 \mathrm{C}$ and $5 \% \mathrm{CO}_{2}$.

Cells, $60-80 \%$ confluent, were transfected in 6-well plates in a ratio of 1 ug of plasmid per $3-4 \times 10^{5}$ cells. The FuGENE 6 Transfection Reagent (Boehringer Mannheim) was used according to the supplier's instructions ( $3 \mathrm{ul}$ of Reagent per 1 ug DNA). Hygromycin B (Boehringer Mannheim) at a concentration of $0.05 \mathrm{mg} / \mathrm{ml}$ (C6) and $0.005 \mathrm{mg} / \mathrm{ml}$ (primary human glioma, HG) was added 48 hours after transfection to select for transfected cells. After one week, concentration of hygromycin B was changed to $0.15 \mathrm{mg} / \mathrm{ml}$ (C6) and $0.015 \mathrm{mg} /$ $\mathrm{ml}(\mathrm{HG})$ and maintained with each change of fresh medium over the next 2-3 months.

\section{Immunocytochemistry}

Parental, non-transfected cells and transfected cells were verified for IGF-I presence by immunoperoxidase technique using anti IGF-I antibodies. Immunocytochemical localization of $\mathrm{MHC1}$ and $\mathrm{B} 7$ antigens was done by immunofluorescence technique. Antibodies targeting rat $\mathrm{MHC}-\mathrm{I}(\mathrm{OX}-18)$ and MHC-II (OX-17), were used (Valbiotech, Paris, France). To stain B-7, a fusion protein CTLA4-Ig was used (Bristol Myers Squib, Seattle, WA, USA). Monoclonal antibodies, labeling human MHC-I (HLA ABC), MHC-II, CD80 and CD86 antigens were applied for direct immunostaining (Becton Dickinson Pharmingen).

\section{RT-PCR}

RNA from cells was isolated using High Pure RNA Isolation Kit (Roche Diagnostics GmbH nr 1828665), and RT PCR was used according Reverse Transcription System Promega Corporation ( $\mathrm{nr}$ A3500).

The following primers were used for RT PCR study of rat IGF-I and rat MHC-I:

forward primer IGF-I: TAGTCCCTGCCTCTTAAGAG,

and reverse primer IGF-I: AGGGGCGTTAAAACTTGGGT;

forward primer MHC-I: ACA CTC GCT GCG GTA TTT CT, and reverse primer MHC-I: CCT TGG CTT TCT GTG TCT CC

(sequence according "rgd" Rat Genome Database).

The following primers were used for RT PCR study of human IGF-I:

forward primer IGF-I: GCATCTCTTCTACCTGGCGCTG,

and reverse primer IGF-I: CAGGCTTGAGGGGTGCGCAATA

(sequence according "rgd" Human Genome Database

Moreover, to verify in another way the presence or absence of IGF-I in parental and transfected cells, the extracted RNA was transformed in cDNA by retrotranscription, and the cDNA was quantified in spectrophotometer Gene Specl (260 and $280 \mathrm{~nm})$.

\section{Results}

The following optimal conditions were established for cell cultures as well of rat C6 glioma as of primary cells

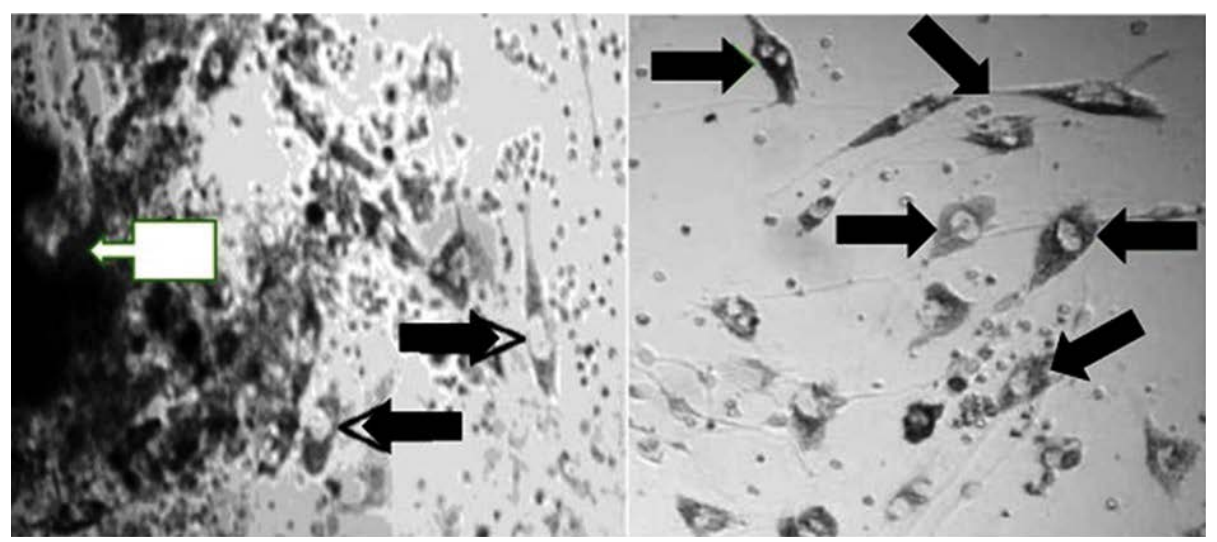

Figure 2: In vitro staining of IGF-1 biomarker in glioma cell culture. The tissue and cells are stained for IGF-1 using anti IGF-1 antibodies applied in immunoperoxidase technique. (left) Five days of culture established from human glioblastoma biopsy. Note the first cells (black/white arrows) proliferating from compact tissue of biopsy (white arrow). The cells in this stage of culture present a relatively weak IGF-I staining. (right) Ten days of the same culture. Note the cells (black arrows) showing much more dark cytoplasm of staining (250X). 


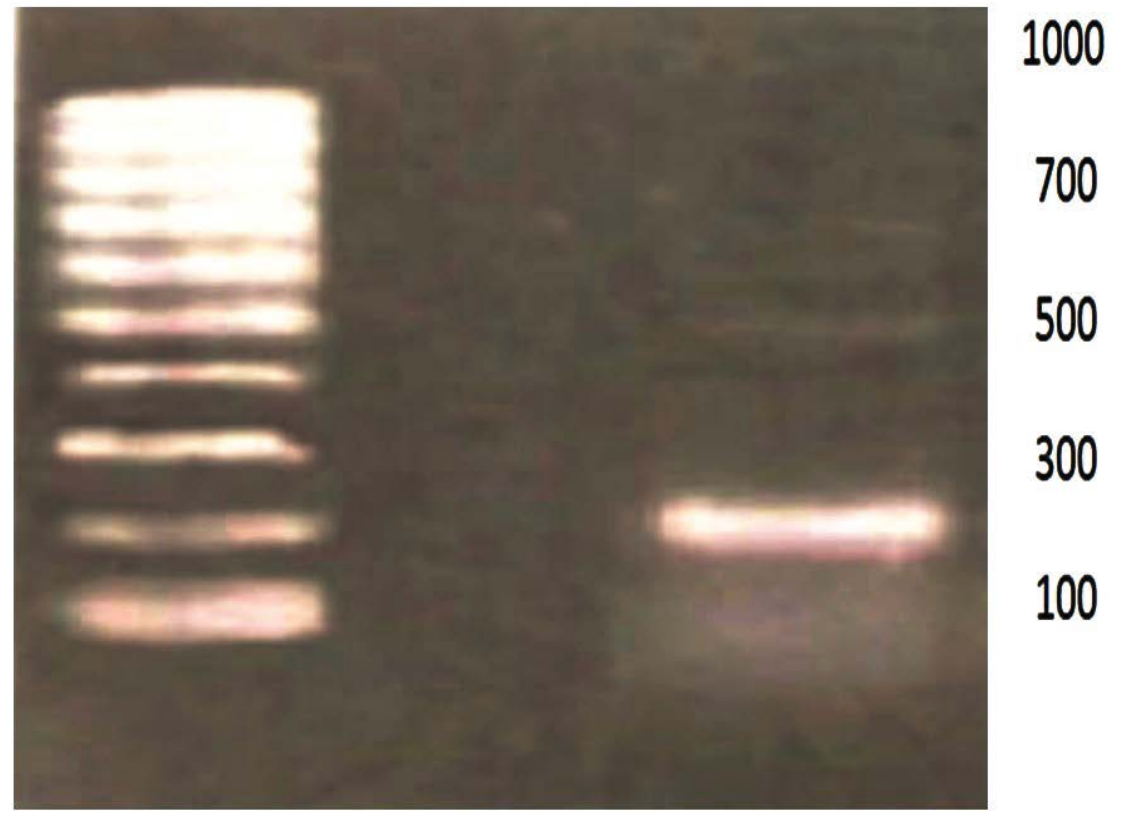

M

a

b

Figure 3: IGF-I expression in C6 glioma cells. RT PCR of "antisense vector" containing MT promoter. a) AS IGF-I cells stimulated with Zn $\mathrm{SO}_{4}$; b) AS IGF-I cells non-stimulated with $\mathrm{ZnSO}_{4}$. M-marker. Note in b) 200 bp bands of amplified DNA using IGF-I primer. The similar results were obtained using human glioma $\mathrm{HG}$ cell line.

Table 1: Identification of presence or absence of IGF-I in C6 cell samples. Quantification of cDNA obtained by retrotranscription of isolated RNA, using spectrophotometer Gene Specl 1 at 260-280 nM. Values between 100 and $300 \mathrm{ng} / \mathrm{ul}$.

\begin{tabular}{|l|l|l|}
\hline Sample & Cells & Concentration of IGF-I cDNA (ng/ul) \\
\hline 1 & Parental cells & 300 \\
\hline 2 & Hela cells & 260 \\
\hline 3 & AS cells & 210 \\
\hline 4 & AS cells & 111 \\
\hline 5 & TH cells & 180 \\
\hline 6 & TH cells & 100 \\
\hline
\end{tabular}

originated from glioblastoma biopsy (Figure 2): DMEM medium supplemented with Glutamax, $10 \% \mathrm{CO}_{2}, 15 \% \mathrm{NBCS}$ (neonatal bovine calf serum), $200 \mathrm{U} / \mathrm{ml}$ of penicillin, $200 \mathrm{ug} /$ $\mathrm{ml}$ of streptomycin, $1.2 \mathrm{ug}$ of amphotericin B, $10.000 \mathrm{ng} / \mathrm{ml}$ of insulin, $5 \mathrm{ug} / \mathrm{ml}$ of transferrin, at $37 \mathrm{C}$.

As to the transfection of glioma cells, the optimum 'timing' was as follows: One week after beginning of $C 6$ cells culture, and three weeks after establishment of primary HG cell line. The confluence of cells as $85-90 \%$ was also the optimum factor. The optimum time to form a complex of transfection was 20 minutes, using transfection reagent: Vector as 1: 1 in the volume $1.5 \mathrm{ul}$ each. The timing of cell transfection was minimum 4 hours, and maximum 6 hours. (The reagent of transfection should be eliminated before 20 hours because of toxicity).

The transfected cells of both antisense and triple helix types showed an inhibition of IGF-I in 50\%-60\% of cell population (Figure 3 and Table 1). They have expressed MHC-I in $30 \%-40 \%$ of cells (Figure 4 and Table 2). After cloning, the
Table 2: Immunocytochemical staining of IGF-I and of immunogenic antigens MHC-I and $-1 \mathrm{II}$, and B7 in the rat glioma C6 cells. NT: Non transfected parental cells; PMT-EP: Transfection with "empty vector"; IGF-I or -II AS: Transfection with IGF-I or IGF-II antisense expression vectors; IGF-I TH: Transfection with IGF-I triple helix expression vector; IGF-I AS/IGF-I TH: Co-transfection with antisense and triple helix vectors; IGF-I AS/MHC-I AS/B7 AS, triple cotransfection; Transfected cells were cultured in presence of $\mathrm{Zn}^{2+}$, in order to activate the MT-I promotor [5,19], (Figure 3 and Figure 4). The similar results were obtained with $\mathrm{HG}$ cells.

\begin{tabular}{|l|l|l|l|l|}
\hline Cells & IGF-I & MHC-I & MHC-II & B7 \\
\hline NT & $++{ }^{*}$ & - & - & - \\
\hline pMT-EP & +++ & - & - & - \\
\hline IGF-I AS & - & ++ & - & ++ \\
\hline IGF-I TH & - & +++ & - & ++ \\
\hline IGF-I AS/IGF-I TH & - & +++ & - & ++ \\
\hline IGF-II AS & +++ & - & - & - \\
\hline IGF-IAS/MHC-IAS/B7AS & - & - & - & - \\
\hline IGF-ITH/MHC-IAS/B7AS & - & - & - & - \\
\hline
\end{tabular}

*++labeling corresponding to maximum intensity of staining (dilution of antibodies 1:200); ++labeling corresponding to intermediate intensity of staining (dilution of antibodies 1:100).

inhibition of IGF-I in both AS and TH cells was demonstrated in $100 \%$ of cells. The antisense or triple helix transfected cloned cultures were stained positively for both MHC-I and B7 antigens in $60-70 \%$ of cells. Moreover, "triple helix" cells compared with antisense cells showed a slightly higher expression of MHC-I (Table 2).

\section{Discussion}

In the current paper we have demonstrated the optimum conditions for cultivation as well rat glioma cells as primary 


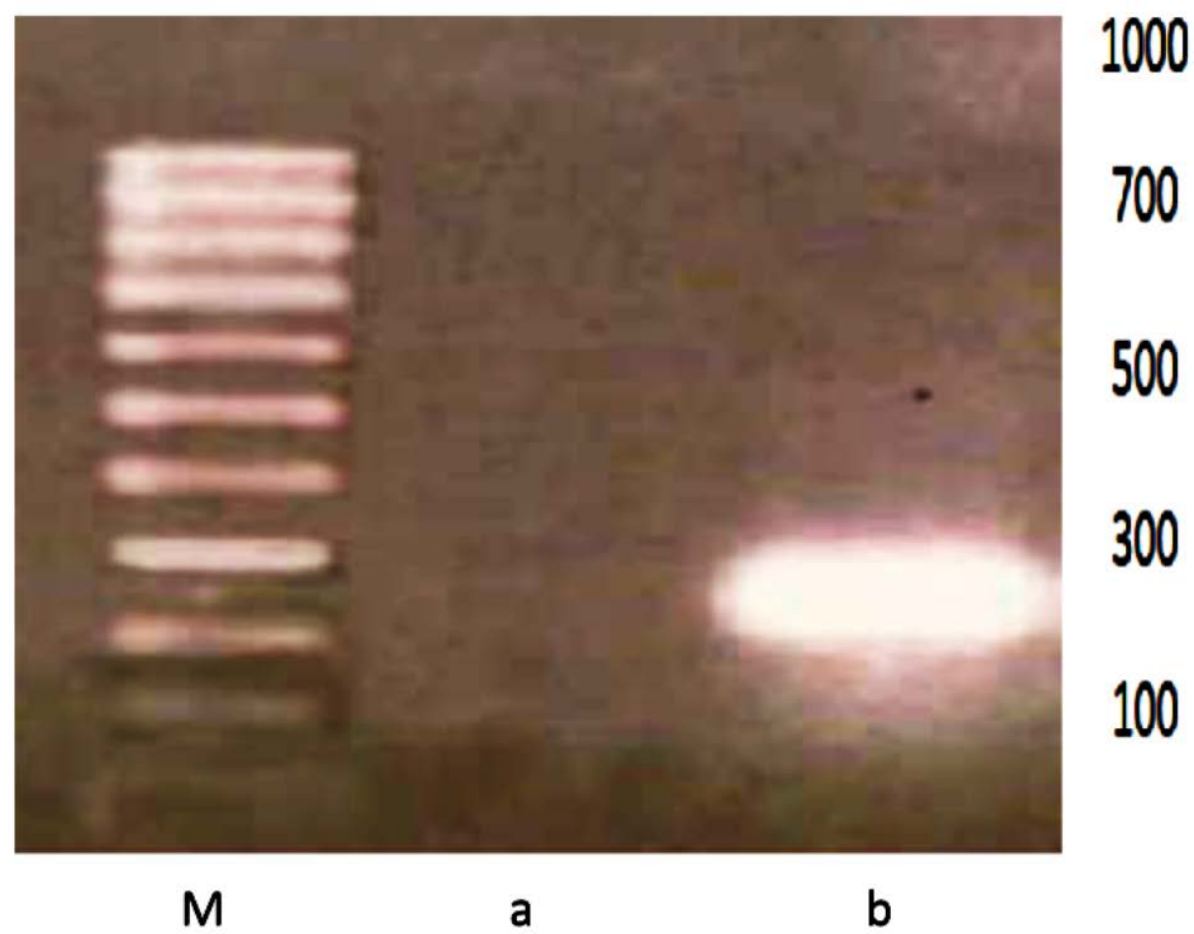

Figure 4: MHC-I expression in C6 glioma cells. RT PCR of "antisense vector" containing MT promoter. a) AS IGFI cells non-stimulated with $\mathrm{ZnSO}_{4}$; b) AS IGF-I cells stimulated with $\mathrm{ZnSO}_{4}$. M-marker. Note in b) 200 bp bands of amplified DNA using MHC-I primer. The similar results were obtained using human glioma HG cell line. Concerning MHC-II and B7 expressions (using MHC-II primer and B7 primer, respectively), the results were identical to those shown for MHC-I.

human glioma cell line. Moreover, we have established the criteria for anti-cancer vaccines: the population of IGF-I AS and IGF-TH transfected cells became more immunogenic thanks to the cloning of cells negative for IGF-I expression. The culture of these transfected cells, totally negative for IGF-I, has permitted to increase two times the number of MHC-I positive cells: From $30 \%$ to $60-70 \%$ cells. The immunogenic character of the transfected cells expressing both MHC-I and B7 antigens, explain their vaccine effect in in vivo tumorigenicity [14-16] (Table 2).

The expression of IGF-I in primary cultures established from glioblastoma biopsies vary between $80-100 \%$. For these reasons, the cultures without total expression were cloned to obtain $100 \%$ IGF-I positive cell line. That was important for the transfection of these cultures using anti-gene IGF-I vectors. After transfection, as mentioned in the paper, only $50-60 \%$ of cells have showed an inhibition of IGF-I. Once more the cloning of cells was performed to obtain $100 \%$ cell population without expression of IGF-I (these transfected cells have also showed an increase in MHC-I expression). The necessity of cloning of cells as well of parental as of transfected cultures was verified in in vivo experimental animal model: Only the 'vaccines' prepared from cloned cells have stopped the development of tumors in $90-100 \%$ cases. No cloned 'vaccines' have stopped the development of tumors only in half of treated animals. For this reason, as far as prognostic importance in human glioblastoma is considered, we have kept the cloning procedure for preparation of vaccines in clinical trial.

As well the AS and $\mathrm{TH}$ vectors preparation, as the in vitro experiments, were repeated for statistical purpose using different cell lines. The results were reproduced every time with the same efficiency. The most important detail concerned the transfection of cells with AS or TH vectors: The choose of MT promotor in prepared vectors permitted to perform the transfection in the same conditions-using always 50-60 micro $\mathrm{M} \mathrm{ZnSO}_{4}$ concentration in culture medium. The IGF-I inhibition performed in these conditions was efficient: The transfected cells, verified in permanently maintained cultures up to six months, were negative for IGF-I presence.

The absence of IGF-I synthesis in "antisense" and "triplehelix" transfected cells, could lead to a compensative increase in IGF-I receptor (tyrosine kinase); IGF-I and IGF-II present in fetal calf serum of culture medium, as well as intracellular IGFII can interact with the type I receptor. Indeed, the increase of IGF-I receptor level could explain the expression of B7. There is a known relation between the signal transduction pathway of tyrosine kinase and the induction of $B 7$ molecules $[13,17,18]$.

The phenotypic modification of transfected cells concerns also the phenomenon of apoptosis [19] (the results not shown). Apoptotic cells, in the context of MHC-I, are recognized by dendritic cell activating lymphocytes T-CD8 [2022]. B7 molecules may also be included in this mechanism, because both MHC-I and B7 molecules are necessary for T cell activation $[15,23]$.

Different immunotherapies and immunogene therapies including antisense strategy to treat glioblastoma has been recently investigated especially in relation to growth factors 
Citation: Trojan J, Quintero G, Ly A, et al. (2019) In vitro Technical Aspects of Anti-Gene IGF-I Vaccines against Glioma. Insights Biomed Res $3(1): 43-48$

[22,24-26]. The immunotherapies therapies of gliomas are in permanent progress $[22,27,28]$.

\section{Acknowledgement}

We are grateful to $\mathrm{Dr}$ G. Pardo (Laboratories Legrand, Bogota) and Dr J. Dib (INS, Bogota) for research subventions, and $\operatorname{Dr}$ A.J. Bermudez for the use of an equipment of his laboratory (INS, Bogota). We thank Drs J.J. Rey and P. Camacho for helpful discussion of the results (UNAB, Floridablanca).

\section{References}

1. Gaillard J, Caillaud JM, Maunoury R, et al. (1984) Expression of neuro-ectoblast in murine teratocarcinomas: Electronmicroscopic and immunocytochemical studies, applications in embryology and in tumor pathology of central nervous system. Bull Inst Pasteur 82: 335-385.

2. Silvia J Bueno, Ricardo Santander, Alvaro Alvarez, et al. (2018) Brain stem cells and IGF-I: Implications in development, regeneration and cancer therapeutics. Integr Mol Med 5: 1-7.

3. Beckner ME, Gobbel GT, Abounader R, et al. (2005) Glycolytic glioma cells with active glycogen synthase are sensitive to PTEN and inhibitors of PI3K and gluconeogenesis. Lab Invest 85: 14571470.

4. Trojan J, Cloix JF, Ardourel MY, et al. (2007) Insulin-like growth factor type I biology and targeting in malignant gliomas. Neuroscience 145: 795-811.

5. Trojan J, Johnson TR, Rudin SD, et al. (1993) Treatment and prevention of rat glioblastoma by immugenic $\mathrm{C} 6$ cells expressing antisense insulin-like growth factor I RNA. Science 259: 94-97.

6. Gene therapy, History 1990s-2010s.

7. Hajeri-Germond M, Naval J, Trojan J, et al. (1985) The uptake of alpha-fetoprotein by $\mathrm{C}-1300$ mouse neuroblastoma cells. $\mathrm{Br} \mathrm{J}$ Cancer 51: 791-797.

8. Rubenstein JL, Nicolas JF, Jacob F (1984) Nonsense RNA: A tool for specifically inhibiting the expression of a gene in vivo. $C R$ Acad Sci III 299: 271-274.

9. Hélène $C$ (1994) Control of oncogene expression by antisense nucleic acids. Eur J Cancer 30: 1721-1726.

10. Dias N, Stein CA (2002) Antisense oligonucleotides: Basic concepts and mechanisms. Mol Cancer Ther 1: 347-355.

11. Sharp PA (2001) RNA interference. Genes Dev 15: 485-490.

12. Pollak MN, Schernhammer ES, Hankinson SE (2004) Insulin-like growth factors and neoplasia. Nat Rev Cancer 4: 505-518.

13. Trojan J (2017) Cancer immunogene therapy. Anti-gene anti IGF-I approach-case of glioblastoma. LAP-Lambert academic publishers, Germany, 1-140.

14. Trojan J, Johnson T, Rudin S, et al. (1994) Gene therapy of murine teratocarcinoma: Separate functions for insulin-like growth factors I and II in immunogenicity and differentiation. Proc Natl Acad Sci 91: 6088-6092.

15. Townsend SE, Allison JP (1993) Tumor rejection after direct costimulation of CD8+ T cells by B7-transfected melanoma cells. Science 259: 368-370.

16. Guo $Y$, Wu M, Chen $H$, et al. (1994) Effective tumor vaccine generated by fusion of hepatoma cells with lymphocytes B cells. Science 263: 518-520.

17. Schwartz RH (1992) Costimulation of T lymphocytes: The role of CD28, CTLA-4 and B7/BBI in interleukin-2 production and immunotherapy. Cell 71: 1065-1068.

18. Jiang R, Mircean C, Shmulevich I, et al. (2006) Pathway alterations during glioma progression revealed by reverse phase protein lysate arrays. Proteomics 6: 2964-2971.

19. François JC, Duc HT, Upegui-Gonzalez LC, et al. (2000) IGF-I triple helix technology changes tumorigenicity of embryonal carcinoma cells by immune and apoptotic effects. Life Sciences 68: 307-309.

20. Albert ML, Sauter B, Bhardwaj N (1998) Dendritic cells acquire antigen from apoptotic cells and induce class I restricted CTLS. Nature 392: 86-89.

21. Kjaergaard J, Wang LX, Kuriyama $H$, et al. (2005) Active immunotherapy for advanced intracranial murine tumors by using dendritic cell-tumor cell fusion vaccines. J Neurosurg 103: 156-164.

22. Dietrich PY, Dutoit V, Tran Thang NN, et al. (2010) T cell immunotherapy for malignant glioma: Toward a combined approach. Curr Opin Oncol 22: 604-610.

23. Pan Y, Trojan J, Guo Y, et al. (2013) Rescue of MHC-1 antigen processing machinery by down-regulation in expression of IGF-I in human glioblastoma cells. PLOS One 8: e58428.

24. Grossman SA, Alavi JB, Supko JG, et al. (2005) Efficacy and toxicity of the antisense oligonucleotide aprinocarsen directed against protein kinase $\mathrm{C}$-alpha delivered as a 21-day continuous intravenous infusion in patients with recurrent high-grade astrocytomas. Neuro-oncol 7: 32-40.

25. Schlingensiepen KH, Fischer-Blass B, Schmaus S, et al. (2008) Antisense therapeutics for tumor treatment: The TGF-beta2 inhibitor AP 12009 in clinical development against malignant tumors. Recent Results Cancer Res 177: 137-150.

26. Hau P, Jachimczak P, Bogdahn U (2009) Treatment of malignant gliomas with TGF-beta 2 antisense oligonucleotides. Expert Rev Anticancer Ther 9: 1663-1674.

27. Love S, Perry A, Ironside J, et al. (2015) Greenfield's neuropathology. ( $9^{\text {th }}$ edn), CRC Press, New York.

28. Trojan J (2018) Brain-from development to neoplasia and gene therapy solution. LAP-lambert academic publishers, Saarbrucken, Germany, 1-150. 